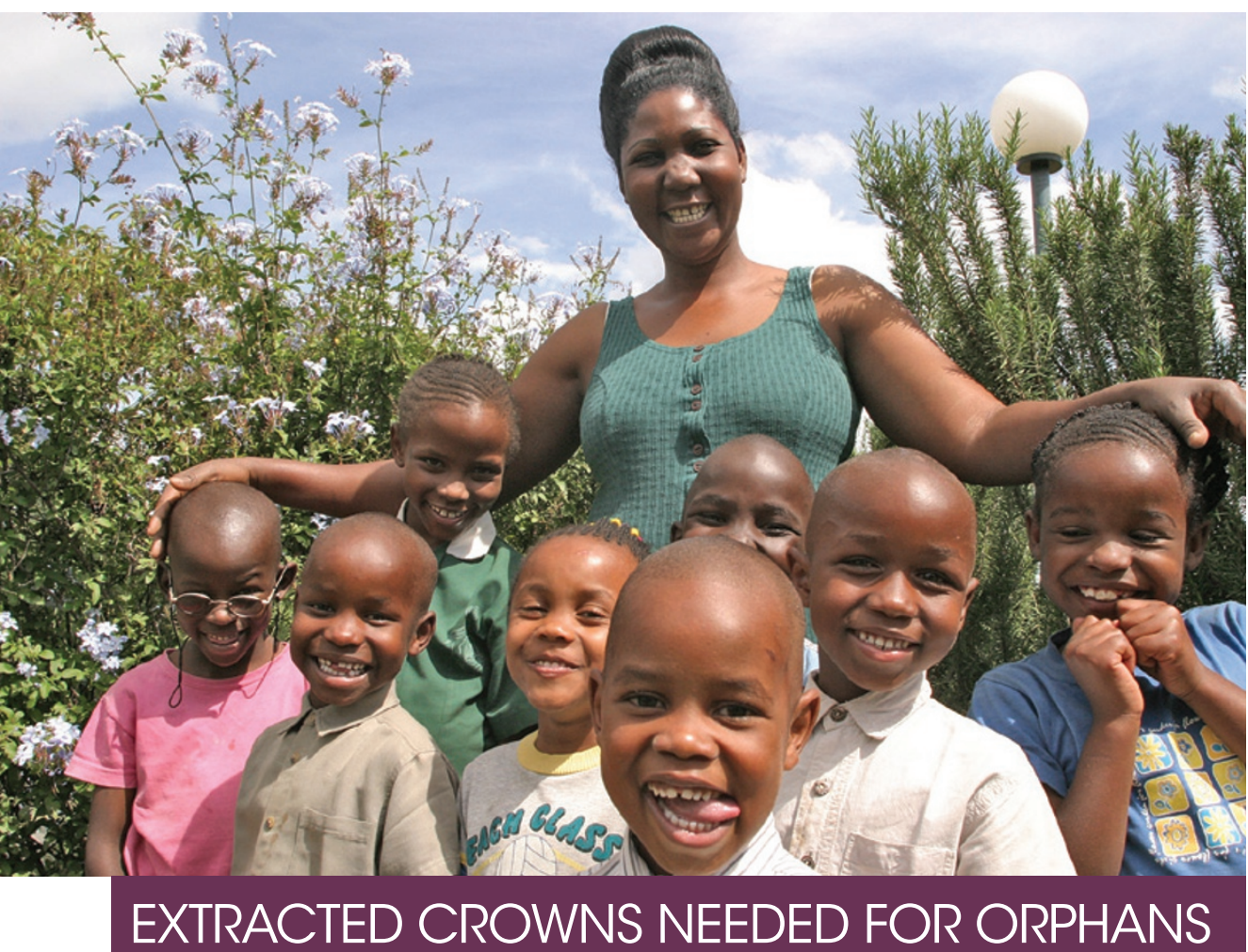

The Swiss recycling company SER is collecting and recycling crowned teeth from dental practices to raise money for the world's largest orphan charity, SOS Children's Villages.

UK dental practices are already participating in the 'Crown Collection' campaign. A tin is placed in the practice, free of charge, and any patient having a metal crown extracted has the option of contributing their crown to the SOS Children's Villages. The crowns are collected by SER, the precious metals are recycled, and the revenue generated from the resale of the metal goes entirely to the charity.

SOS Children provides a family for life for children who have lost their parents through conflict, famine, natural disaster, disease and poverty. Over 78,000 orphaned and abandoned children are cared for by SOS mothers in clusters of family homes in 508 Children's Villages, in 124 countries around the world. A further million children benefit from SOS Children's outreach support.

Dentist John Ahearne agreed to hosting a tin at his practice and gradually the tin has been filled with patients' crowns. 'The whole process couldn't be simpler', commented Dr Ahearne.

Dental practices who would like to have an SOS Children crown donation tin can contact SER on freephone number 08001412611 or email infosos@ser-preciousmetal.com.

\section{XYANTHE'S HARD WORK IS RECOGNISED}

Proactive dental nurse Xyanthe Lambert, who organised an E-Petition to protest against the cost of the Annual Retention Fee (ARF), has been named Dental Nurse of the Year by online resource The Dental Nurse Network.

Via a Facebook group that she set up and through writing to Vital and elsewhere, Xyanthe, a senior dental nurse, radiographer and oral health educator, encouraged other dental nurses to sign the petition. Xyanthe believes that the ARF fee should be tiered to reflect the salaries of each group of dental care professional (DCP)

'I am so proud to have been voted Dental Nurse of the Year,' said Xyanthe. 'It means so much to me. I don't think of myself as an exceptional nurse who does their job, but one person who works as part of a team to make a difference.

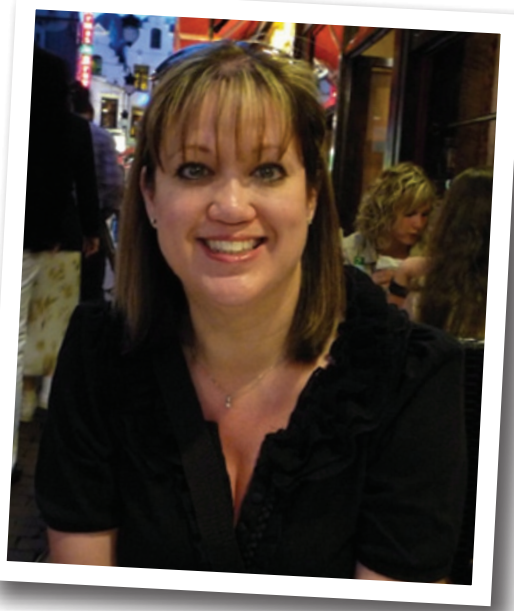

MAJOR CHILD TOOTH DECAY TRIAL PLANNED

Hundreds of UK dental practices will be invited to participate in a major trial, 'FiCTION', to assess the benefits of three different methods of managing tooth decay in children.

Over $40 \%$ of children in the UK are already experiencing obvious decay in their primary teeth by age five, a statistic that has remained largely unchanged for the past 20 years. Only around $12 \%$ of obviously decayed baby teeth in 5-yearolds are treated with fillings, while the vast majority are left untreated, and dental extractions remain the most common reason for children in the UK to receive an out-patient general anaesthetic.

The three methods being tested in the FiCTION trial are: using only preventative techniques recommended in national guidance; conventional fillings with preventive techniques; and biological treatment of the decay with preventive techniques. The study is also examining what the children, all aged between three and seven, think of the different types of treatment.

'There is, as yet, no conclusive evidence for the most effective approach to managing decay in baby teeth, said $\mathrm{Dr}$ Nicola Innes, one of the lead researchers for the trial. 'With this trial we are looking to provide that evidence.

The trial has been commissioned by the National Institute for Health Research Health Technology Assessment (NIHR HTA) and is led by the Universities of Dundee and Leeds, working with colleagues at the Universities of Cardiff, Glasgow, London, Newcastle and Sheffield.

The main trial is expected to begin early in 2012 and will involve around 200 dentists across the UK.

www.fictiontrial.info

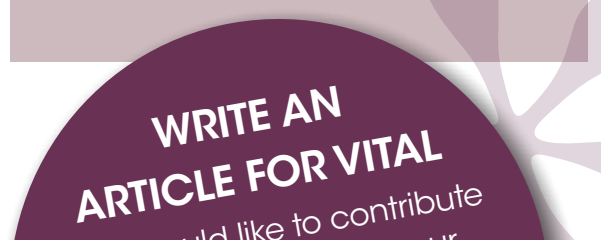

If you would like to cond your to Vital, please sen first draft to idea, proposal or tist com or vitaleditorial@nalutial, NPG, write to Vital Editeet, London

4-6 Crinan st 9XW. 